\title{
CRISE DA EDUCAÇ̃̃O ESCOLAR E PERCEPC̣ÕES DOS PROFESSORES SOBRE $O$ SEU TRABALHO: IDENTIDADE PROFISSIONAL E CLIMA DE ESCOLA EM ANÁLISE
}

Fátima Pereira*

Ana Mouraz**

RESUMO: Apresentam-se resultados parciais de um projeto intitulado "Aprendizagens e climas de escola: dispositivos inovadores para o sucesso escolar" que procurou, essencialmente, produzir conhecimento em dois domínios nucleares das formas de vida produzidas na escola, as aprendizagens e os climas, e conhecer a especificidade dos processos educativos e relacionais, relativos aos dois focos citados, experienciados em diferentes escolas que pertencem ao Observatório da Vida das Escolas do Centro de Investigação e Intervenção Educativas (CIIE) da Faculdade de Psicologia e de Ciências da Educação da Universidade do Porto. $\mathrm{O}$ artigo foca a dimensão do clima na sua relação com o trabalho docente, apresentando e discutindo os resultados de um questionário sobre a percepção dos professores a propósito das atividades que realizam na escola e o sentido educacional que lhes atribuem, realçando-se, ainda, o questionamento sobre as preocupações profissionais que fundamentam a realização dessas atividades. Discutidos a partir de uma problemática que considera a crise da escola e a identidade dos professores, os resultados permitiram salientar que os professores mantêm como primeira fonte de identidade profissional a relação pedagógica que desenvolvem com os alunos e a ação instrumental da educação escolar.

Palavras-Chave: Trabalho docente. Clima de escola. Crise da educação escolar. Identidade profissional.

\footnotetext{
* Doutora em Ciências da Educação e Professora Auxiliar da Faculdade de Psicologia e de Ciências da Educação da Universidade do Porto. Membro da Comissão Científica do Centro de Investigação e Intervenção Educativas e da Comissão de Ética da Universidade do Porto. Vice-coordenadora do Serviço de Educação Contínua (FPCEUP). E-mail: fpereira@fpce.up.pt

* Doutora em Ciências da Educação. Investigadora e Coordenadora do Observatório da Vida das Escolas do Centro de Investigação e Intervenção Educativas da Faculdade de Psicologia e de Ciências da Educação da Universidade do Porto. E-mail: anamouraz@fpce.up.pt
} 


\title{
SCHOOL EDUCATION CRISIS AND TEACHERS' PERCEPTIONS ON THEIR WORK: PROFESSIONAL IDENTITY AND SCHOOL CLIMATE ANALYSIS
}

\begin{abstract}
This paper presents some results from the project entitled "Learning and School Climate: Innovative Devices to Educational Achievement," which aimed essentially at producing knowledge in two nuclear domains of forms of life inside the school: the learnings and the school climates. The project also intended to understand the specificity of the educational and relational processes related to these domains, which was experienced at different schools associated to the Observatory on School Life (OBVIE), part of the Educational Research and Intervention Center (CIIE) and the Faculty of Psychology and Sciences of Education of Porto University (FPCEUP). This article focuses on the school's climate dimension in its relation to teachers' work. It presents and discusses results from a questionnaire concerning teachers' perception of their professional school activities, and the educational sense teachers make of them. It highlights the questioning about teachers' professional worries, which are behind the realization of these activities. Results were discussed from a perspective framed by school crisis and teachers' identity. The main findings show that teachers have their professional identity primarily established by both: their pedagogical relation with students and the instrumental action at school.
\end{abstract}

Keywords: Teacher's work. School climate. School education crisis. Professional identity.

\section{INTRODUÇÃO}

O Observatório da Vida nas Escolas (OBVIE) ${ }^{1}$ pertence ao Centro de Investigação e Intervenção Educativas (CIIE) da Faculdade de Psicologia e de Ciências da Educação da Universidade do Porto (FPCEUP) e pretende constituir uma rede de saberes alicerçada nas valências de investigação do centro, integradora de contributos emergentes de projetos de investigação - cujo objeto e/ ou campo de estudo considerem a escola e a sua heterogeneidade e complexidade epistemológicas - desenvolvidos nas diferentes áreas de investigação do CIIE; pretende ainda constituir parcerias com instituições, associações e projetos a partir das quais se possam partilhar saberes e informações e construir conhecimento novo com base nessa partilha. O OBVIE atualmente desenvolve a sua atividade em parceria com 16 agrupamentos de escolas que abrangem escolas de educação pré-escolar e do ensino básico e secundário da área geográfica da FPCEUP. Um dos projetos de investigação que deu vida à parceria com os agrupamentos de escolas intitula- 
se "Aprendizagens e climas de escola: dispositivos inovadores para o sucesso escolar" e pretendeu: implementar uma rede de recolha de informação fundamentada na utilização de metodologias de investigação e no estabelecimento de protocolos visando ao acesso a dados atualizados sobre a vida nas escolas; produzir conhecimento em dois domínios nucleares das formas de vida produzidas na escola, designadamente: as aprendizagens e os climas; conhecer a especificidade dos processos educativos e relacionais, relativos aos dois focos citados, experienciados em diferentes escolas; criar dispositivos de divulgação sistemática e atualizada do conhecimento produzido; possibilitar debates prospetivos com as comunidades, educativa e científica sobre os resultados da atividade do observatório. O projeto pretendeu, portanto, identificar e revelar as práticas pedagógicas, curriculares e organizacionais das escolas parceiras do OBVIE, que possibilitassem a auto e hétero reflexão, e pudessem ser proactivas da atividade dos professores e das escolas.

Neste artigo, explicitamos algumas das problemáticas que orientam a investigação realizada no OBVIE, referenciais teóricos focados na articulação entre o clima de escola, o trabalho docente e a identidade profissional dos professores que permitem discutir alguns dos resultados do projeto de investigação referido, que também aqui se apresentam.

\section{CRISE DA EDUCAÇÃO ESCOLAR E NOVOS MANDATOS AO TRABALHO DOS PROFESSORES}

Os dispositivos de regulação e de estabilização da identidade institucional escolar têm sofrido profundas rupturas, e a sua reinvenção configura-se como algo de difícil realização (cf. Pereira, 2010). Esse fenômeno, não sendo recente (tem emergido e temse complexificado no processo de massificação e alargamento da escolaridade obrigatória), tem originado ao longo das últimas décadas a produção de medidas legislativas em diferentes domínios do campo educativo, no sentido de possibilitar a adaptação institucional às mudanças sociais, tecnológicas e económicas. A educação escolar em Portugal tem sido, por isso, objeto de sucessivas reformas de âmbito curricular, organizacional e administrativo que pretenderam responder, quer à complexidade e conflitualidade emergentes da situação do que se tem designado por crise da instituição escolar e da profissionalidade docente (cf. Correia \& Matos, 2001), quer aos 
imperativos sociopolíticos e econômicos que resultam dos processos de democratização e de modernização da sociedade portuguesa e da inserção de Portugal na União Europeia.

Diversos estudos têm realçado o insucesso dessas reformas e revelado níveis preocupantes de insucesso e de abandono escolar em Portugal e uma crescente perda de legitimidade das funções sociais da Escola e dos saberes que ensina (Pereira, 2011). Por outro lado, os contextos educativos formais caracterizam-se hoje por profundas instabilidades que traduzem uma complexidade de percepções, de representações e de relações vividas cotidianamente no interior da escola, que se articula com outros contextos sociais e neles se repercute, designadamente, os contextos familiares e de trabalho (cf. Pereira, 2009; Mouraz, 2004, 2005).

Os novos mandatos sociais sobre a educação escolar e os discursos que os acompanham, designadamente nos domínios formativo e científico, colocam novos desafios à instituição educativa que requerem uma abordagem problematizadora e esclarecedora da sua interpretação pelas comunidades educativas. As representações simbólicas e cognitivas e as determinações sociais produzidas por esses mandatos configuram novas concepções de profissionalidade docente e novas formas de educar na Escola, que a investigação em educação deve contribuir para compreender, fundamentar e legitimar. A situação atual de crise da Escola relaciona-se com o desmoronamento do consenso social alargado sobre os princípios universais que organizaram a instituição escolar e com uma ruptura com os mandatos de natureza ética, social e ontológica sobre o trabalho dos professores (que disponibilizava regimes de justificação estáveis e configurava padrões de ação não sujeitos à crítica); tal fato origina a vivência cotidiana de interações de risco, isto é, interações caracterizadas pela imprevisibilidade sobre o comportamento do outro e que podem derrapar para a entropia, a qualquer momento (cf. DEROUET, s.d.). Essa realidade instabiliza as formas de vida na instituição educativa, com implicações na formação das identidades individuais e sociais que é suposto a Escola contribuir para formar e que é imperativo a investigação em educação contribuir para esclarecer.

Os professores e as escolas são confrontados com novos mandatos sociais incompatíveis com os princípios organizadores da escola tradicional moderna: a intersubjetividade, a individualização do ensino, o desenvolvimento da autonomia, do espírito crítico e da expressividade, o respeito pelas diferenças, a produção de saberes, o trabalho de projeto, a qualificação para o trabalho, etc. A unidade dos princípios e dos valores que caracterizava a instituição educativa 
foi substituída por uma diversidade de princípios de ação e de normas de justiça que constitui um espaço de tensões e de conflitos que obriga os professores a um constante trabalho de produção de sentido e de justificação, que se reflete na relação que desenvolvem com os alunos e na dimensão ética da educação, traduzida em novos modos de socialização e de subjetivação escolar que, no entanto, se encontram em boa parte por conhecer (PEREIRA, 2007).

A confrontação com a ineficácia das sucessivas reformas para resolver uma crise que cada vez mais afeta os cotidianos escolares, a legitimidade da educação escolar e a visibilidade dos seus benefícios em termos individuais e sociais, alterou as lógicas de intervenção do Estado na educação escolar, que agora se consubstancia em medidas legislativas de territorialização da política educativa. Essas medidas situam-se, sobretudo, nos domínios organizacional, curricular e administrativo e transferem para as comunidades escolares a responsabilidade pela resolução dos problemas que afetam o campo educativo (LEITE, 2006).

A territorialização das políticas educativas a que se assistiu na década passada pluralizou o campo de legitimação dos regimes de justificação da educação escolar em cada escola e situação educativa concretas, em que os professores e os alunos sofrem cotidianamente as tensões entre o que é justo e o que é ajustado, entre a necessidade de disciplinar e o imperativo socioético de emancipar, entre os princípios da igualdade e as práticas de seleção. Entidades simbólicas como a autonomia, a responsabilidade, a flexibilização curricular, a participação, a inclusão, o professor reflexivo, o professor investigador, o trabalho em projeto e o trabalho em equipa, entre outras, têm sido apropriadas pela administração e pelos atores que habitam o campo da justificação da educação escolar, sem que essa apropriação se traduza numa refundação dos modos de pensar e organizar a ação educativa que possibilite uma transformação dos contextos educativos e das condições de aprendizagem dos alunos.

Acresce ainda referir que a década de 1990, em Portugal, evidenciou um paradoxo socioescolar resultante de efeitos cruzados entre o acréscimo de qualificações escolares e o acréscimo de desigualdades sociais e entre o desemprego estrutural de massas e a crescente desvalorização dos diplomas, que obrigou a reequacionar a escolarização num quadro societal mais lato (CANÁRIO, 1999). Segundo o mesmo autor, a emergência de novas modalidades de exclusão social associada ao acréscimo de qualificações escolares produz uma relação complexa entre a exclusão social e a exclusão escolar que se focaliza numa transfiguração da questão social, 
outrora estabelecida na unidade conflitual das sociedades industriais modernas, que opunha o trabalho ao capital, e agora assente na fratura entre os que estão integrados e os que estão excluídos.

A produção da exclusão relativa de que o sistema escolar é responsável está inscrita na sua matriz obrigacionista, universalista e expansionista, ou seja, ao alargar-se a escolarização obrigatória como requisito para a integração social e o acesso ao mundo do trabalho, não se criando condições para o sucesso escolar generalizado, aumenta-se exponencialmente o número daqueles que lhes não poderão aceder. A exclusão escolar e a exclusão social relacionam-se, então, por "laços de causalidade circular" (CANÁRIO, 1999, p. 49). Essa situação revela-se particularmente dramática nas designadas "zonas difíceis" e para as também designadas "crianças em risco".

As transformações implicadas em novas configurações identitárias e em novas condições socioculturais e econômicas geradas no contexto social atual afetam os cotidianos das escolas, das crianças e dos jovens, dos professores e das famílias, instabilizando as formas de justificar e de legitimar as práticas escolares e exigindo novos mandatos institucionais, que incidem na relação educativa e nos saberes escolares, na organização institucional e no lugar social da educação escolar e das suas relações com o trabalho. $\mathrm{O}$ insucesso e o abandono escolares constituem um dos problemas essenciais da educação escolar em Portugal, que tem contribuído para colocar Portugal em posições desfavoráveis no contexto dos sistemas educativos europeus; mas, sobretudo, ele põe em causa as possibilidades de a Escola se assumir como uma instituição capaz de promover a igualdade de oportunidades e a democratização social; de promover a qualificação de todos os portugueses e a inclusão social.

\section{CLIMA DE ESCOLA, TRABALHO DOCENTE E IDENTIDADE PROFISSIONAL}

O clima de escola é um conceito que, nas últimas duas décadas, tem sido mobilizado frequentemente na análise do trabalho dos professores e dos seus efeitos na educação e sucesso escolar dos alunos (ALDRIDGE, LAUGKSCH, \& FRASER, 2006; FISHER \& FRASER, 1991). Definido de uma forma elementar, o clima de escola refere-se ao ambiente psicossocial percebido e experienciado por todos aqueles que constituem a escola e que se mantêm por um período de tempo capaz de conferir alguma estabilidade a essas perceções e conferir-lhes alguma identidade que o diferencia de outros contextos similares; esse ambiente é constituído pelas crenças e valores partilhados, pelas estruturas cognitivas e pelas atitudes que 
condicionam as interações no espaço escolar (ANDERSON, 1982). O clima de escola está, por isso, relacionado com os significados, as emoções e os afetos que se desenvolvem na escola, traduzindo os padrões de relação entre as pessoas e os grupos. Como as relações são sempre mediadas pelas atividades que se realizam e pelos comportamentos que se exprimem, estes condicionam e são condicionados pelo clima de escola. O clima transmite mensagens sobre a vida na escola e permite perpetuar uma visão particular da realidade que é partilhada pelos membros que a constituem (cf. CHANG, CHUANG, \& BENNINGTON, 2011); ele influencia a experiência profissional dos professores e a qualidade das experiências educacionais dos alunos.

Em termos teóricos, o conceito de clima remonta à teoria de campo de Lewin (1936) que salienta a importância, na formação das identidades e dos comportamentos, do campo vital produzido na interação entre o indivíduo e o ambiente em que este se insere em cada momento. No caso do clima de escola, a abordagem fundamenta-se ainda na consideração desta enquanto organização social, beneficiando, com as devidas adequações, da extensa pesquisa realizada sobre o clima organizacional das empresas (ANDERSON, 1982) e estabelece relações teóricas com o campo da administração educacional (HUANG \& FRASER, 2009).

A cultura de escola pode ser considerada uma das dimensões do clima mais relevantes para a compreensão da implicação das perspectivas e atividades do professor no clima escolar e das suas relações com a profissionalidade docente. A cultura refere-se a padrões de relação e de interação que se produzem na escola e que condicionam as formas de estar, de ser e de agir em contexto escolar (McLAREN, 1991). A cultura produz-se, por isso, a partir das características das pessoas e dos grupos e da matriz organizacional e institucional da escola. Os professores são parte fundamental dessa matriz. Por isso, a profissionalidade dos professores relaciona-se intrinsecamente com o clima de escola, condicionando-o e sendo por ele condicionada.

O conceito de profissionalidade docente integra a ideia de "profissão em ação" (CUNHA, 1999, p. 132) e realça o lugar do professor na construção da sua prática profissional e da profissão, configurando-o na sua subjetividade específica e definindo-o como um sujeito biográfico e sociohistórico. Gimeno Sacristán (1995) refere que a profissionalidade se relaciona com o que é específico na ação docente - os comportamentos, os conhecimentos, as destrezas, as atitudes e os valores - e que se encontra em permanente elaboração em função dos contextos dessa ação. No entanto, 
a profissionalidade docente não pode ser perspectivada como estando dependente unicamente de quem a realiza e, pelo contrário, a responsabilidade sobre a prática educativa não pode ser imputada ao professor individualmente; esta relaciona-se com um conjunto de outras práticas que a condicionam, designadamente as práticas organizacionais, e com as expectativas e representações que se produzem na escola. A profissionalidade docente tem, então, uma dimensão simbólica referenciada pelas concepções sobre a profissão que, individual e coletivamente, se comunicam na escola. A profissionalidade docente relaciona-se ainda com a identidade profissional e os processos da sua construção.

Como refere Dubar (1997), a identidade social resulta de duas transações, uma interna ao indivíduo e outra externa, estabelecida entre o indivíduo e as instituições com as quais interage. A identidade profissional docente é uma das dimensões da identidade social dos professores e constrói-se, em grande parte, através das interações comunicacionais que se realizam na escola. Essas interações são mediadas por dimensões organizacionais de tipo formal e informal que se articulam com as atividades docentes realizadas e se configuram em função das intencionalidades e racionalidades que as fundamentam. Sleegers e Kelchtermans (1999) realçam também que a identidade profissional dos professores resulta de significados provisórios sobre si próprios e sobre a profissão que eles produzem na interação com o ambiente profissional que se vive, fundamentalmente, na escola.

Lopes (2008, p. 72), considerando que a atual crise da identidade dos professores tem uma relação intrínseca com a crise da modernidade, refere que é necessário considerar duas ideias essenciais para se elaborar a superação dessa crise: primeiro, as transformações a que assistimos, e que têm sido designadas por diferentes termos tais como modernidade tardia ou pós-modernidade, são de tipo sistémico, o que alerta para a consideração das mudanças dos professores de modo contextualizado, designadamente em termos sociopolíticos e escolares; e segundo, a ideia de que

[...] o essencial da crise é de tipo subjetivo. A mudança das leis e até das estruturas são tentativas de resposta a uma mudança mais essencial, a da base subjetiva da modernidade - os modos de vida, de relação, de ser e de conhecer - sem o que a modernidade se reduziria a um invólucro sem vida e sem sentido.

A autora salienta que se trata sobretudo de uma crise de (com)vivência num mundo vivido partilhado, mas que já não o é. Zoll (1992, cit. in LOPES, 2008) refere-se a essa crise como uma crise da normalidade, no sentido em que as convenções sociais que 
antes eram evidentes e inquestionáveis são agora postas em causa, e sujeitas à crítica e à reflexão e até mesmo destruídas; a crise de normalidade é acompanhada de profundas mudanças nas estruturas de habitus e de identidade.

Nesse contexto de crise de identidade profissional, o clima de escola é sem dúvida uma das dimensões mais relevantes para compreender as possibilidades de configuração de respostas à situação de crise identitária; enquanto ambiente psicossocial, o clima condiciona as práticas sociais e educativas e as representações que se constroem a seu propósito e que integram a construção cognitiva do agir social na Escola que informa a construção das identidades.

Como referem Tardif e Lessard (2005), as recentes abordagens conceptuais sobre o trabalho docente reconhecem plenamente a importância de se partir do conhecimento situado sobre a atividade dos professores. Num contexto de intensificação e de complexificação do trabalho dos professores, a dimensão interativa da docência constitui a sua essencialidade, que se exprime nos contextos escolares, "a docência, enquanto trabalho de interações, apresenta ela mesma alguns traços particulares que estruturam o processo de trabalho cotidiano no interior da organização escolar" (TARDIF \& LESSARD, 2005, p. 11).

Pensar o trabalho docente na sua dimensão relacional e interativa significa, então, situar a análise no ambiente escolar e relativamente ao seu objeto de trabalho que são as relações humanas e a comunicação entre professores e alunos. As percepções dos professores a esse propósito constituem parte de um conhecimento incontornável para se compreender a realidade escolar e as possibilidades da sua transformação. Por isso, o objetivo do recorte analítico que se faz neste texto pretende interpretar as percepções dos professores sobre seu próprio trabalho, tendo em conta concepções de clima de escola, identidade profissional e profissionalismo docente.

\section{ASPECTOS METODOLÓGICOS}

Como já foi referido, os resultados aqui apresentados focam uma das dimensões de pesquisa do projeto "Aprendizagens e climas de escola: dispositivos inovadores para o sucesso escolar". O projeto desenvolveu-se ao longo de três anos, cruzando dois eixos de investigação: as práticas de ensino e de aprendizagem e o clima de escola. Entre as dimensões estudadas relativas ao clima de escola deu-se relevo ao trabalho docente que constitui o foco do 
presente trabalho. Para o efeito construiu-se e administrou-se um questionário que procurou conhecer a percepção dos professores sobre as atividades que realizam na escola e o sentido educacional que lhes atribuem, realçando-se ainda as preocupações profissionais que fundamentam a realização dessas atividades. Em termos técnicos, o questionário era constituído por uma primeira parte de caracterização dos professores e uma segunda parte de caracterização dos climas de escola tal como são percebidos pelos professores a partir das preocupações sobre seu próprio trabalho e a identificação das práticas mais frequentes que mobilizam a ação do coletivo de professores das escolas envolvidas no estudo. A construção do questionário foi produzida a partir do inventário de eixos significativos da ação dos professores que a literatura identifica como fundamentais (KANTOROVA, 2009; TABLEMAN, 2004) e que o estudo maior de onde este recorte foi extraído havia sustentado. Os itens tinham a forma de escala ordinal de tipo lickert, com sete intervalos, em que um (1) correspondia à irrelevância, o quatro (4) à importância e o sete (7) à imprescindibilidade. A passagem dos questionários foi proposta às escolas, utilizando a tripla modalidade de formato on-line, formato digital que era devolvido via e-mail e formato de papel, devolvido nesse suporte. Considerando que a multiplicidade de suportes do questionário se destinava a facilitar o preenchimento e envio do mesmo, não se entendeu relevante distinguir as análises consoante o meio técnico de recolha e envio. Foram recolhidos e tratados estatisticamente duzentos e dezesseis (216) questionários.

\section{ANÁLISE DOS DADOS}

O questionário continha 70 itens agrupados em duas subescalas semelhantes, uma sobre "As principais atividades e as preocupações a que se dedicam os professores da escola a que pertence" o respondente e a outra destinada a identificar "A preocupação pessoal dos professores" respondentes. Como referido, as subescalas eram semelhantes nos itens que as constituíam, apenas se diferenciando a estrutura verbal dos mesmos para corresponder aos dois focos em análise: o coletivo dos professores ou o próprio professor respondente. $\mathrm{Na}$ presente análise foram seleccionados $60(30+30)$ itens, agrupados de acordo com as categorias que a literatura evidencia como relevantes para a caracterização do trabalho dos professores: político; comunicacional; pedagógico/didático; colaborativo e burocrático. Essas categorias 
sustentam a caracterização dos climas de formação presentes nas instituições de ensino básico e secundário porquanto identificam as tendências percebidas pelos professores como enquadradoras do seu trabalho nas escolas (KANTOROVA, 2009; TABLEMAN, 2004). Por essa razão organizaram-se os 30 itens do questionário em associação às categorias referidas para caracterizar o trabalho dos professores. O trabalho de agregação dos itens para o presente estudo foi realizado posteriormente à passagem do questionário, antes referido, e validado estatisticamente. A associação entre categorias e itens é a constante da Tabela 1, para o que se calcularam os valores de fidelidade inter itens (usou-se o índice de fidelidade alfa de (ronbach), tendo-se apurado valores muito bons.

Foram associados à categoria do "político" os itens que configuram uma preocupação própria dos professores e dos seus pares que se associa à perspectiva política da sua ação cotidiana, que é assim qualificada porque ganha um sentido mais geral e transcende a mera ação individual de cada professor, tendo implicações no equilíbrio social para que a ação educativa contribui. Na categoria comunicacional foram agregados os itens que valorizam, sobretudo, a dimensão comunicativa da educação que se exerce sobre os alunos, mas que se faz no seio de uma comunidade educativa cada vez mais alargada, com quem é necessário partilhar objetivos e tarefas (TARDIF \& LESSARD, 2005). Na categoria relativa ao trabalho pedagógico-didático incluíram-se os itens que tendencialmente focavam o trabalho curricular do professor e as condições necessárias ao seu desenvolvimento e melhoria. Na categoria relativa à colaboração, deu-se ênfase ao trabalho colaborativo entre professores, pelo que se agregaram os itens que o referiam explicitamente. Na última categoria, associaram-se os itens relativos ao cumprimento de tarefas de cariz mais burocrático ou formal que habitualmente se associam à dimensão do "dever ser".

O poder explicativo do modelo reside, ainda, na possibilidade de permitir sustentar que os climas de escola são diferenciáveis, consoante os professores que nelas trabalham reconhecem algumas daquelas tendências como predominantes no trabalho dos seus colegas em sintonia com as suas preocupações, ou não. Daí que a lista de itens acima referida possa caracterizar a importância das categorias no enquadramento do trabalho dos professores e que a mesma lista seja capaz de poder diferenciar os climas de escola, caracterizados pela verificação dos níveis de importância das tendências que 
TABELA 1: Associação entre itens e categorias que caracterizam o trabalho dos professores.

\begin{tabular}{|c|c|c|}
\hline Categorias & Itens & $\begin{array}{c}\text { Fidelidade } \\
\text { inter itens } \\
\text { ( } \alpha \text { de } \\
\text { Cronbach) }\end{array}$ \\
\hline Político & $\begin{array}{l}1 \text { Cumprimento das metas do Projeto Educativo } \\
15 \text { Adequação da oferta educativa às necessidades dos alunos } \\
20 \text { Questões de discriminação e exclusão } \\
26 \text { Justiça da ação educativa junto dos alunos } \\
30 \text { Concretização de ideais democráticos } \\
32 \text { Reflexão sobre a ação da Escola } \\
35 \text { Inclusão de grupos de alunos desfavorecidos }\end{array}$ & 0,899 \\
\hline $\begin{array}{l}\text { Comuni- } \\
\text { cacional }\end{array}$ & $\begin{array}{l}2 \text { Promoção do bem-estar, das relações e da comunicação entre os } \\
\text { alunos das respectivas turmas } \\
4 \text { Promoção das relações entre a escola e o meio } \\
6 \text { Organização das estruturas pedagógicas } \\
7 \text { Animação sociocultural da escola } \\
9 \text { Promoção das relações com Pais e E. de Educação } \\
12 \text { Resolução de conflitos } \\
18 \text { Manutenção da disciplina e do respeito dentro do espaço escolar } \\
31 \text { Imagem exterior da escola }\end{array}$ & 0,887 \\
\hline $\begin{array}{l}\text { Pedagó- } \\
\text { gico/didá- } \\
\text { tico }\end{array}$ & $\begin{array}{l}5 \text { Melhoria do trabalho com os alunos a nível da sala de aula } \\
16 \text { Reconhecimento (pela Direção) da atividade pedagógica e } \\
\text { científica desenvolvida } \\
17 \text { Aprofundamento da formação na respectiva área de docência } \\
19 \text { Experimentação de práticas pedagógicas e didáticas inovadoras } \\
21 \text { Reconhecimento (pelos alunos) da atividade pedagógica e } \\
\text { científica desenvolvida } \\
22 \text { Organização de tarefas de aprendizagem relevantes } \\
25 \text { Avaliação da eficácia do ensino aprendizagem que promove } \\
27 \text { Desenvolvimento de projetos na escola } \\
29 \text { Dinamização de estratégias pedagógicas diversas }\end{array}$ & 0,939 \\
\hline $\begin{array}{l}\text { Colabo- } \\
\text { rativo }\end{array}$ & $\begin{array}{l}8 \text { Desenvolvimento de trabalho cooperativo com os outros } \\
\text { professores } \\
10 \text { Desenvolvimento de boas relações com os pares } \\
13 \text { Promoção do sentimento de equipe entre os membros dos } \\
\text { grupos de trabalho onde se inclui }\end{array}$ & 0,876 \\
\hline $\begin{array}{l}\text { Burocrá- } \\
\text { tico }\end{array}$ & $\begin{array}{l}3 \text { Cumprimento de questões burocráticas } \\
\text { 11Cumprimento da legislação, das normas e dos deveres } \\
24 \text { Cumprimento de orientações pedagógicas e curriculares }\end{array}$ & 0,739 \\
\hline
\end{tabular}


correspondem ao descrito nos itens. Finalmente, essa verificação dos níveis de importância fica a cargo de quem conhece bem essas condições de trabalho, isto é, os próprios professores agora investidos da possibilidade de ajuizar a sua ação, em contraponto com a ação dos demais colegas da respectiva escola.

Não se incluíram cinco itens, que não estavam associados diretamente às categorias criadas, tendo sido utilizados como variáveis explicativas das respostas dos professores. Assim utilizam-se os itens 14. Reconhecimento político (ou a sua falta) da especificidade e exigência da profissão; 23. Favorecimento do espírito competitivo dos estudantes; 28. Melhoria dos resultados escolares; 33. Adequação ao trabalho das lideranças; 34 . Desenvolvimento da carreira profissional, da subescala "A preocupação pessoal dos professores respondentes", para esse fim.

Os resultados foram estudados a partir das variáveis independentes, idade, gênero, anos de trabalho na escola atual, e testadas as diferenças significativas. Realizaram-se análises comparativas capazes de identificar o peso de cada um destes fatores, nomeadamente quando se tratava de variáveis com opções de resposta mais distribuídas. Analisaram-se ainda as diferenças entre as categorias das duas subescalas. Usaram-se análises univariadas (ANOVA). Em todos os casos, um valor de p inferior a 0,05 foi considerado significativo. Todos os dados foram tratados pelo recurso ao programa SPSS, Versão 18.

\section{PERCEPC̣ÕES E OPINIÕES DOS/AS PROFESSORES/AS}

A apresentação dos resultados organiza-se em torno de duas dimensões de análise: "As principais atividades e as preocupações a que se dedicam os professores das escolas" e "A preocupação pessoal dos professores". Em cada uma dessas dimensões, destacam-se os resultados que nos permitirão realizar uma reflexão interpretativa e pertinente para pensar o trabalho docente e o clima de escola.

O grupo inquirido tinha as seguintes características:

- $179(82,9 \%)$ eram professoras e $37(17,1 \%)$ eram professores;

- $25(11,2 \%)$ tinham até 30 anos de idade, $78(36,3 \%)$ entre 31 e 40 anos, $66(30,7 \%)$ entre 41 e 50 anos e $47(21,9 \%)$ tinham mais de 50 anos de idade; 
- quanto à habilitação acadêmica, $9(4,2 \%)$ tinham o bacharelado, $186(86,9 \%)$, licenciatura, $18(8,4 \%)$, mestrado e $1(0,5 \%)$ tinha outra habilitação não especificada;

- a média de tempo de serviço era de 17 anos no total e de 6 anos de serviço na escola onde lecionam atualmente.

A essas variáveis independentes acrescentaram-se, como atrás foi referido, as variáveis mediadoras correspondentes a três dos cinco itens não incluídos nas categorias do trabalho docente, transformados em variáveis dicotômicas, considerando a maior ou menor valorização do item, para o que se usou o nível cinco como ponto de corte.

\section{ATIVIDADES E PREOCUPAC̣̃̃ES A QUE SE DEDICAM OS PROFESSORES DAS ESCOLAS}

De um modo geral, a apreciação que os professores respondentes fazem acerca das prioridades da ação dos colectivos das escolas em que trabalham é muito positiva em todas as dimensões consideradas, como se constata na boxplot ${ }^{2}$ da Figura 1. Verifica-se que a mediana (representada pelo traço grosso que divide as caixas) das respostas se situa perto do nível 6 que correspondia ao grau de "quase imprescindível". Verifica-se uma média ligeiramente mais elevada nas dimensões relativas ao trabalho colaborativo e ao trabalho burocrático, quando comparadas com as restantes dimensões do trabalho docente, mas essas diferenças não são significativas. Também o valor da dispersão das respostas (desvio padrão) é maior nessas duas dimensões a que se acrescenta a dimensão comunicacional do trabalho.

Quando se analisou a influência das variáveis independentes e moderadoras nesses resultados, constatou-se que a pertença ao ensino secundário dos respondentes $(\mathrm{N}=57)$ estava relacionada com níveis de valorização inferiores das dimensões política, pedagógica, comunicacional e burocrática, quando comparadas com os valores obtidos no tratamento das respostas dos professores que pertenciam ao ensino básico $(\mathrm{N}=93)$. Os valores de significância foram, respectivamente, $0.013 ; 0.02 ; 0.004 ; 0.011$. Também o tempo de trabalho prestado na escola ajuda a explicar as diferenças de importância atribuídas à dimensão pedagógico-didática. Foram os professores com menos de três anos de trabalho naquela escola $(\mathrm{N}=101)$ que atribuíram mais importância aos itens incluídos nessa dimensão $(p=0.036)$, quando comparados com os seus colegas que aí trabalhavam há mais tempo $(\mathrm{N}=103)$. 
FIGURA 1 - Boxplot relativo aos resultados globais das cinco dimensões, relativas ao modo como os respondentes qualificam o trabalho docente dos colegas de escola.

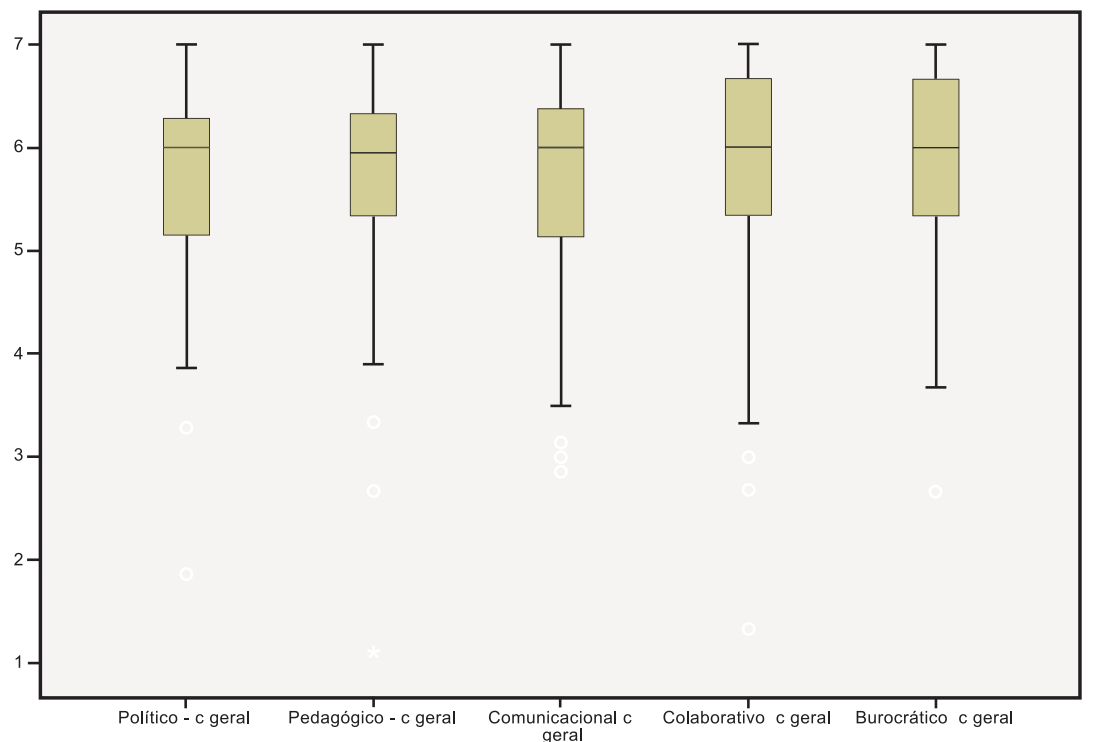

Quanto às variáveis moderadoras, relativas à maior ou menor importância atribuída ao reconhecimento político da profissão (item14), ao favorecimento do espírito competitivo dos estudantes (item23), à preocupação com o desenvolvimento da carreira profissional (item34), constatou-se que os níveis mais elevados nesses itens correspondiam a níveis mais elevados em todas as dimensões consideradas, sendo as diferenças significativas (refere-se de novo que se dividiram os respondentes consoante haviam pontuado aqueles itens, sendo o valor 5 o ponto de corte). As diferenças são todas significativas $(\mathrm{p}=0.000)$.

\section{PREOCUPAC̣ÃO PESSOAL DOS PROFESSORES}

A segunda dimensão do questionário inquiria sobre as principais preocupações que norteavam a ação individual do professor, na sua intervenção na escola. Os professores respondentes apreciam muito positivamente o seu próprio trabalho e preocupações docentes, mais ainda do que se constatou na apreciação feita sobre o trabalho dos pares. Os níveis da mediana são superiores ao nível 6 (seis), e a dispersão é menor que a verificada na análise anterior. A dimensão melhor pontuada é a relativa ao trabalho colaborativo dos professores. 
FIGURA 2 - Boxplot relativo aos resultados globais das cinco dimensões, relativas ao modo como os respondentes qualificam 0 trabalho e as preocupações próprias

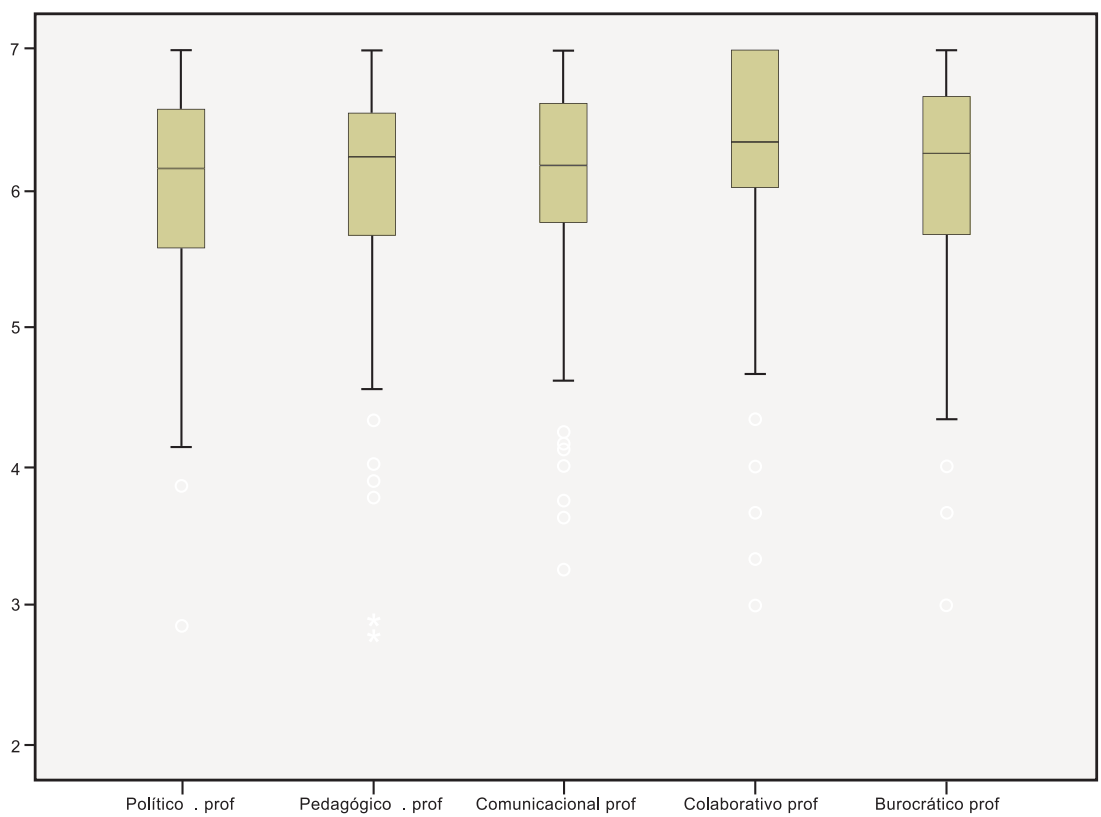

Ao analisarem-se as relações passíveis de poder explicar alguns desses resultados globais, constatou-se que, das variáveis independentes, apenas o tempo de trabalho prestado na escola atual explicava diferenças nas categorias relativas ao trabalho pedagógico, à dimensão comunicacional e à componente burocrática da atividade docente. Os professores com "menos tempo de casa" $(\mathrm{N}=101)$ valorizaram mais essas dimensões como caracterizando as suas preocupações e práticas do que se apurou para os professores com mais tempo de serviço naquela escola $(\mathrm{N}=103)$. A diferença era significativa nos três aspectos, respectivamente para valores de $\mathrm{p}=0.021 ; 0.045 ; 0.025$.

A exemplo do constatado na apreciação sobre as preocupações dos pares, também os professores evidenciaram diferenças na apreciação do seu próprio trabalho se fossem divididos consoante as respostas dadas aos itens transformados em variáveis moderadoras, relativos à maior ou menor importância atribuída ao reconhecimento político da profissão, ao favorecimento do espírito competitivo dos estudantes, à preocupação com o desenvolvimento da carreira profissional. As diferenças são todas significativas $(p=0.000)$, o que permite inferir que os professores que estão mais preocupados com o reconhecimento 
político da profissão e com o seu desenvolvimento profissional também valorizam mais as cinco dimensões caracterizadoras do trabalho docente. Igualmente, os professores que favorecem mais o espírito competitivo dos estudantes são também os mais preocupados com os aspectos caracterizadores da sua ação profissional.

Analisamos depois se existiam diferenças entre esses itens, tal como haviam sido pontuados pelo grupo dos professores, para caracterizar "as suas preocupações próprias" quando comparados com os valores obtidos na versão da pergunta que inquiria sobre "as preocupações dominantes da maioria dos professores da sua escola". Tal como se constata na figura 3, as repostas são todas elas favoráveis à opinião dos professores sobre a sua própria ação (caixas cuja legenda é: burocrático prof; colaborativo prof; comunicacional prof; pedagógico prof e político prof).

FIGURA 3 - Boxplot relativo aos resultados globais das cinco dimensões, comparativas entre a apreciação geral dos professores da escola e a preocupação própria.

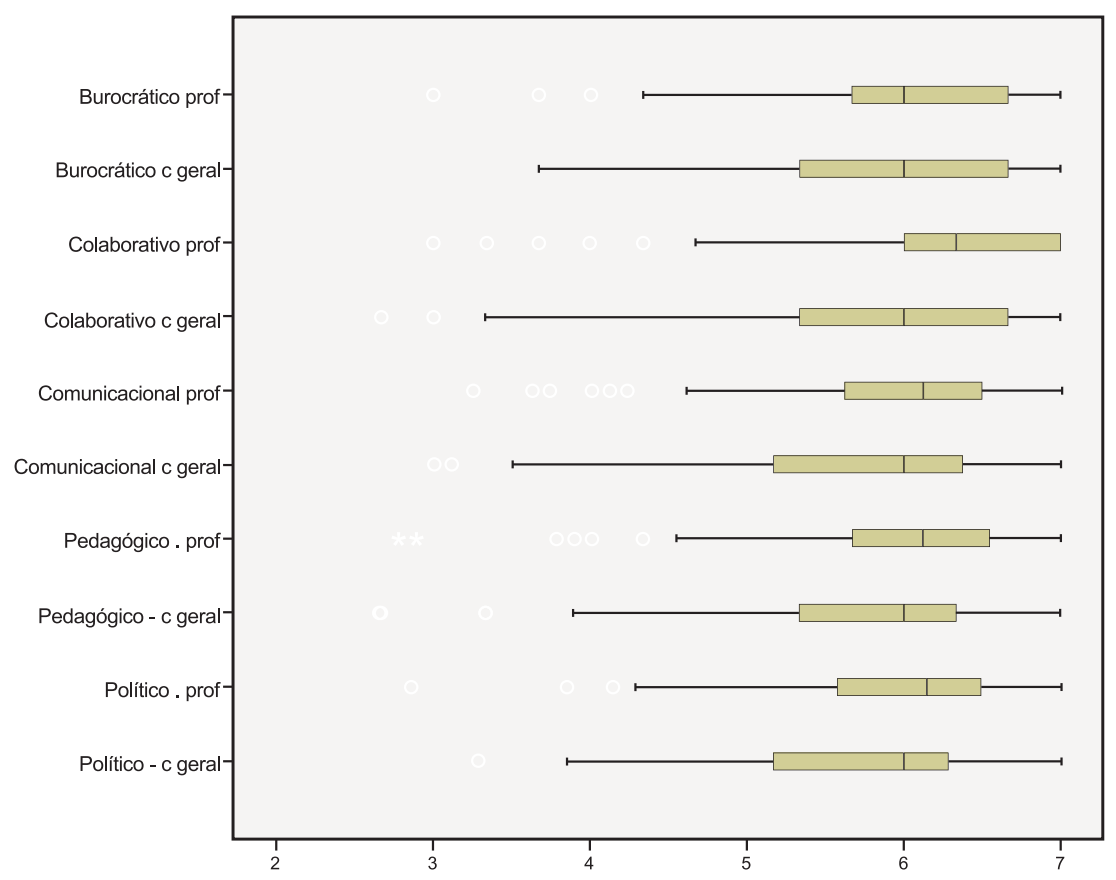


Finalmente, particularizou-se a análise para identificar os itens individuais onde se registraram valores mais elevados nas duas subescalas e valores mais dispersos.

Os itens que os professores valorizaram mais e de modo mais consensual, quando se referiam à ação coletiva da maioria dos professores da sua escola quer à sua ação individual, foram os itens 11, 24, 26, 28, respectivamente, Cumprimento da legislação, das normas e dos deveres; Cumprimento de orientações pedagógicas e curriculares, Justiça da ação educativa junto dos alunos e Melhoria dos resultados escolares.

Já na subescala relativa às preocupações pessoais e individuais dos respondentes, há um grupo de itens que atinge os valores mais elevados constituído por: 2- Promoção do bem-estar, das relações e da comunicação entre os alunos das (respectivas) turmas, 5- Melhoria do trabalho com os alunos a nivel da sala de aula, 9- Promosão das relações com Pais e E. Educação, 10- Desenvolvimento de boas relações com os pares, 18- Manutenção da disciplina e do respeito dentro do espaço escolar.

Quanto aos itens onde não se encontraram diferenças entre os dois pontos de vista em foco (o do coletivo dos professores da escola e o do respondente) e que também obtiveram valores de importância globalmente mais baixos, eles são: 3-Cumprimento de questões burocráticas, 7-Animação sociocultural da escola, 16-Reconhecimento - pela Direção - da atividade pedagógica e científica desenvolvida, 24Cumprimento de orientações pedagógicas e curriculares, 27-Desenvolvimento de projetos na escola, 28-Melhoria dos resultados escolares e 33-Adequação do trabalho das lideranças. Os itens, individualmente considerados onde há menor consenso, pese embora as medianas não se distanciarem muito dos restantes itens, são o 14 e o 23 , respectivamente: Reconbecimento político (ou a sua falta) da especificidade e exigência da profissão e Favorecimento do espírito competitivo dos estudantes. Serve essa especificidade para identificar aqueles aspectos que os professores respondentes menos valorizam na sua ação, talvez porque considerem que diz menos sobre a especificidade da sua profissão.

Em resumo, considerando as categorias em que se agruparam os itens, não se encontraram diferenças significativas na importância global de cada uma delas, relativamente às restantes, nas duas subescalas. Todavia, pertencer ao ensino básico faz diferença (positiva) no modo como os professores valorizam as dimensões, política, pedagógica, comunicacional e burocrática. Estar há pouco tempo naquela escola está diretamente associado à valorização dos aspectos pedagógicos, se comparado com os valores obtidos por quem está há mais tempo. 


\section{CLIMA DE ESCOLA E TRABALHO DOCENTE: ALGUNS SIGNIFICADOS PARA PENSAR A EDUCAÇÃO ESCOLAR}

Tendo em conta que os professores respondentes consideram de forma mais consensual todas as dimensões caracterizadoras da ação docente, quando comparados com as preocupações dos seus pares manifestas na sua ação coletiva, parece-nos estarmos perante um conjunto de percepções que traduzem quer a multidimensionalidade da profissionalidade docente, quer a intensificação da sua regulação (sentida individualmente) por força de normas e de políticas curriculares. Igualmente a maior valorização dos aspectos burocráticos em detrimento da dimensão política assim o confirma. Tal ideia configura o núcleo do trabalho docente na atualidade nessas escolas, mas converge com outros estudos de âmbito nacional e internacional (cf. PEREIRA, 2011; POPKEWITZ, 2002). Assim, a autonomia profissional, expressão do exercício profissional como o de uma ação de cariz político, parece não fazer parte das percepções mais significativas dos professores sobre o trabalho dos seus pares. Já os aspectos associados a uma dimensão ética da profissão, exercida no trato cotidiano com os demais atores educativos (dimensão comunicacional), são consensualmente considerados como parte das suas preocupações. É interessante realçar que essas percepções são, de algum modo, paradoxais no sentido em que a dimensão ética da profissão se associa a um elevado grau de profissionalismo que tem na autonomia docente a sua máxima expressão. O profissionalismo docente é uma concepção socialmente construída e que diz respeito às características do conhecimento de que os professores são portadores, à autonomia com que exercem a profissão e às funções sociais do seu trabalho (cf. HOYLE \& JOHN, 1995). Essa construção social realiza-se em diferentes instâncias de construção da profissão das quais a escola representa o lugar social mais relevante. É na escola que se constrói grande parte das representações e das imagens que configuram a construção da identidade profissional dos professores e do seu profissionalismo. Como refere Korthagen (2004), a tomada de consciência sobre essas representações e imagens permite também aos professores consciencializarem-se sobre o seu conhecimento profissional prático, integrando-o na concepção que constroem sobre a profissão e sobre a sua identidade.

O fato de a maior dispersão nas respostas sobre as preocupações dos seus pares e a sua ação coletiva e individual na escola incidir na animação sociocultural da escola, no reconhecimento político 
da especificidade e exigência da profissão e no favorecimento do espírito competitivo dos estudantes revela-nos que essas dimensões são periféricas na consideração da profissionalidade docente nesse grupo de professores. Se considerarmos a dimensão comunicacional/ interacional do trabalho docente, a que fizemos referência sobretudo a partir de Tardif e Lessard (2005), a não convergência de respostas em torno da animação sociocultural como atividade que ocupe e preocupe os professores pode indiciar que a interação é percebida e vivida mais num registro clínico e interindividual do que sociocultural. Esse aspecto é ainda relevante para inferir algumas considerações sobre o clima de escola, pese embora não nos podermos referir a dados sobre escolas específicas, mas apenas de uma forma genérica. Com efeito parece que as percepções dos professores realçam sobretudo a dimensão mais intersubjetiva e inefável do clima de escola, ignorando a cultura que caracteriza esse clima.

Interessa salientar que, no que diz respeito às principais preocupações que norteiam a ação individual do professor na sua intervenção na escola, surgem com valores mais elevados a promoção do bem-estar das relações e da comunicação entre os alunos das respectivas turmas, a melhoria do trabalho com os alunos a nivel de sala de aula, a promoção das relações com pais e encarregados de educação, o desenvolvimento de boas relações com os pares e a manutenção da disciplina e do respeito dentro do espaço escolar. Embora não surpreenda que sejam essas as dimensões mais valorizadas pelos professores, pois todas elas convergem direta ou indiretamente para a educação dos alunos, que é o foco das preocupações profissionais dos professores, é interessante notar que são valores de tipo comunicacional e colaborativo os que são evidenciados. A centração das preocupações e atividades dos professores na sala de aula e nas respectivas turmas e a relativa desvalorização que é atribuída aos itens agregados na dimensão política traduzem uma tendência para a não consideração da dimensão organizacional da escola como fator de configuração da atividade profissional, que também converge com outros estudos realizados (cf. PEREIRA, 2011). A dimensão organizacional é fundamental para a configuração da cultura de escola, e a sua não evocação sugere que podemos estar perante climas focados no individualismo profissional e numa organização institucional pouco participada. Esses últimos dados sugerem alguma ausência de consciencialização entre os coletivos das escolas, acerca da importância da formação (colaborativa) em contexto escolar e do clima de escola para o desenvolvimento profissional e para a educação dos alunos. 
É ainda pertinente constatar que o reconhecimento político externo da profissão e o favorecimento do espírito competitivo dos estudantes são os itens que recolhem menor consenso, a exemplo do que já tinha acontecido nas respostas sobre o que os professores consideram que são as principais atividades e preocupações dos seus pares. Por outro lado, a dispersão nas respostas sobre a preocupação com o reconhecimento político (ou a sua falta) da especificidade e exigência da profissão pode ser interpretada como reflexo de identidades profissionais mais restritas do que alargadas e por isso mais centradas na dimensão pedagógica e burocrática da educação escolar e menos no seu lugar social e nos mandatos sociopolíticos que a condicionam. A ser assim quase se poderia concluir que, para esses professores, a identidade profissional depende fundamentalmente do modo como exercem o seu trabalho pedagógico dentro da sala de aula, em estrito cumprimento das exigências burocráticas da profissão e menos em resposta coletiva às exigências sociais que a sua tarefa de educadores lhes coloca.

\section{CONCLUSÕES}

Ao longo deste artigo explicitamos o enquadramento teórico-metodológico e a problemática de um estudo, realizado no âmbito do OBVIE e no contexto epistemológico do projeto "Aprendizagens e climas de escola: dispositivos inovadores para o sucesso escolar", que pretendeu conhecer a percepção de professores sobre as atividades que realizam na escola e o sentido educacional que lhe atribuem, realçando-se as preocupações profissionais que fundamentam essas atividades.

A intensificação e complexificação do trabalho docente e os novos desafios que se colocam à educação escolar, em resultado das rupturas sofridas pelos dispositivos de regulação e de estabilização da identidade institucional escolar, fundamentam a importância de se compreender as percepções dos professores não só sobre o seu trabalho, mas também sobre o dos seus pares.

A articulação que se fez neste texto sobre as percepções dos professores sobre seu próprio trabalho e a questão do profissionalismo docente permite relacioná-las com o clima de escola. Tal acontece porquanto implica conhecer os significados que se produzem na comunicação e nas relações escolares e que condicionam a interpretação que os professores realizam sobre a sua ação educativa e a forma como a integram na construção da sua 
identidade. Como referimos, a cultura de escola, constituindo uma das principais dimensões do clima, integra os padrões de relação e de interação que se produzem e que condicionam as formas de estar, de ser e de agir em contexto escolar. Por outro lado, a identidade dos professores constrói-se num processo que integra uma dupla transação - biográfica e interna, e contextual e externa - e resulta de significados provisórios sobre si próprio e sobre a profissão que se constituem na interação com o ambiente profissional. Clima de escola, identidade profissional e trabalho docente são por isso três polos da profissionalidade cuja articulação teórico-metodológica e epistemológica beneficiam a compreensão da complexidade que, atualmente, afeta o trabalho dos professores e a educação escolar.

Os resultados que apresentamos permitem-nos salientar, todavia, que a interação privilegiada do conjunto dos respondentes se faz com os alunos o que determina a ideia de que os professores mantêm como primeira fonte de identidade profissional a relação pedagógica e a ação técnica da educação escolar, conduzindo ao que antes intitulamos como uma identidade profissional restrita. Importaria, por isso, investigar as condições em que uma identidade profissional alargada pudesse ser fomentada, isto é, de que modo as representações sobre o trabalho docente pudessem ser consciencializadas a partir do mandato social e cultural da educação que a escola, cada escola, faz seu.

\section{REFERÊNCIAS}

ALDRIDGE, J. M., LAUGKSCH, R. C., \& FRASER, B. J. (2006). School-level environment and outcomes-based education in South Africa. Learning Environments Research, 9, 123-147.

ANDERSON, C. S. (1982). The search for school climate: a review of the research. Review of Educational Research, 52(3), 368-420.

BERGER, G. (1992). A investigação em educação: Modelos sócio-epistemológicos e inserção institucional. Revista de Psicologia e de Ciências da Educação, 3/4, 23-26.

CANÁRIO, R. (1999). Exclusão social e exclusão escolar. Noesis, 49, 48-50.

CHANG, C.-P., CHUANG, H.-W., \& BENNINGTON, L. (2011). Organizational climate for innovation and creative teaching in urban and rural schools. Qualitity \& Quantity, 45, 935-951.

CORREIA, J. A., \& MATOS, M. (2001). Solidões e solidariedades nos quotidianos dos professores. Porto: ASA.

CUNHA, M. I. (1999). Profissionalização docente: Contradições e perspectivas. In: I. VEIGA \& M. I. CUNHA (Orgs.). Desmistificando a profissionalização do magistério (p. 127-147). São Paulo, Campinas: Papirus. 
DEROUET, J.-L. (s.d.). Souffrance au travail dans l'enseignement et impératif de justification: Note sur la construction scientifique d'un problème social. Disponível em: $<$ http://www.ac-reims.fr/mic/actua_academie/pages_actu/sem_souffrance_interv1. pdf>. Acesso em: 20 abr. 2006.

DUBAR, C. (1997). A socialiração: Construção das identidades sociais e profissionais. Porto: Porto Editora.

FISHER, D. L., \& FRASER, B. J. (1991). School climate and teacher professional development. South Pacific Journal of Teacher Education, 19, 17-23.

HOYLE, E., \& JOHN, P. D. (1995). Professional knowledge and professional practice. Londres: Cassell.

HUANG, S.-y L., \& FRASER, B. J. (2009). Science teachers' perceptions of the school environment: gender differences. Journal of Research in Science Teacbing, 46, 404-420.

KORTHAGEN, F. (2004). In search of the essence of a good teacher: Towards a more holistic approach in teacher education. Teaching and Teacher Education, 20, 77-97.

KANTOROVA, J. (2009). The school climate: Theoretical principles and research from the perspective of students, teachers and parents. Odgojne znanosti, 11(1), 183-189.

LEITE, C. (2006). Políticas de currículo em Portugal e (im)possibilidades da escola se assumir como uma instituição curricularmente inteligente. Curriculo sem Fronteiras, 6(2), 67-81.

LEWIN, K. (1936). Principles of topological psychology. Nova Iorque: McGraw.

LOPES, A. (2008). Marcos e marcas das políticas de educação na (re)construção da identidade profissional dos professores portugueses: Rumo a uma política pedagógica. In: J. A. LIMA \& H. R. PEREIRA (Orgs.). Políticas públicas e conbecimento profissional: A educação e a enfermagem em reestruturação (p. 69-112). Lisboa: Legis Editora.

McLAREN, P. (1991). Decentering cultures postmodernism, resistance, and critical pedagogy. In: N. B. WYNER (Ed.). Current perspectives on the culture of schools (pp. 231-257). Brookline: Brookline Books.

MOURAZ, A. (2004). Das práticas educativas familiares à participação dos pais no desenvolvimento do currículo escolar dos seus filhos: sentido e limites. In: J. A. da COSTA, A. NETO-MENDES \& A. VENTURA (Orgs.). Políticas e gestão local da educação. Aveiro: Universidade de Aveiro.

MOURAZ, A. (2005). Cursos tecnológicos, entre a educação e o trabalho: representações de pais e professores. Um estudo de caso. In: A. M. MARTINS, C. P. SOUSA \& L. A. PARDAL (Orgs.). Representações sociais, competências e trajectórias profissionais. Ed. em CD-Room. Aveiro: Universidade de Aveiro.

PEREIRA, F. (2007). Discursos sobre a infância em formação inicial de professores Portugal nas últimas décadas. Linhas Críticas, v. 13, n. 25, jul-dez, 165-184.

PEREIRA, F. (2009). Conceptions and knowledge about childhood in initial teacher training: Changes in recent decades and their impact on teacher professionality and on schooling in childhood. Teaching and Teacher Education, 25(8), November, 1009-1017.

PEREIRA, F. (2010). Infância, educação escolar e profissionalidade docente. Um mapeamento social dos discursos em formação inicial de professores. Lisboa: Fundação Calouste Gulbenkian e Fundação para a Ciência e a Tecnologia.

PEREIRA, F. (2011). In-service teacher education and scholar innovation: The semantics of action and reflection on action as a mediation device. Australian Journal of Teacher Education, 36(11), article 3, 33-50. 
POPKEWITZ, T. S. (2002). Cultural productions: (Re)constituting the nation, the child \& teacher in the educational sciences. Lisboa: Educa/FPCEUL.

SACRISTAN, G. (1995). Consciência e acção sobre a prática como libertação profissional dos professores. In: A. NOVOA (Org.). Profissão professor (p. 63-92). Porto: Porto Editora.

SLEEGERS, P., \& KELCHTERMANS, G. (1999). Introduction to the theme issue: teachers' professional identity. Pedagogisch Tijdschrift, 24(4), 369-373.

TABLEMAN, B. (2004). School climate and learning. Best Practices Briefs, 31, 1-10.

TARDIF, M., \& LESSARD, C. (2005). O trabalho docente: Elementos para uma teoria da docência como profissão de interações humanas. Petrópolis: Vozes.

\section{NOTAS}

${ }^{1}$ http://www.fpce.up.pt/ciie/obvie. (Acesso em: 2 ago. 2014.)

${ }^{2}$ Utilizam-se boxplot (caixas de bigodes) para apresentação dos resultados em virtude do seu poder comunicativo. Ao representar cada variável numa caixa "com bigodes", ficam indicadas visualmente as medianas, as dispersões, os quartis, os outliers, e todos esses elementos podem ser vistos em comparação com as restantes variáveis que se incluem na mesma figura.

Recebido: 20/01/2014

Aprovado: 01/09/2014

Contato:

Universidade do Porto

Faculdade de Psicologia e de Ciências da Educação

Rua Alfredo Allen, 4200-135

Porto | Portugal 